\title{
Transportation Conditions for Prompt Use of Ex Vivo Expanded and Freshly Harvested Clinical-Grade Bone Marrow Mesenchymal Stromal/Stem Cells for Bone Regeneration
}

\author{
Elena Veronesi, PhD, ${ }^{1}$ Alba Murgia, PhD, ${ }^{1}$ Anna Caselli, PhD, ${ }^{2}$ Giulia Grisendi, PhD, ${ }^{1}$ \\ Maria Serena Piccinno, BSc, ${ }^{1}$ Valeria Rasini, $\mathrm{PhD},{ }^{1}$ Rosaria Giordano, MD, ${ }^{3}$ Tiziana Montemurro, PhD, ${ }^{3}$ \\ Philippe Bourin, MD, PhD, ${ }^{4, *}$ Luc Sensebé, MD, PhD, ${ }^{5}$ Markus T. Rojewski, PhD, ${ }^{6}$ \\ Hubert Schrezenmeier, MD, PhD, ${ }^{6}$ Pierre Layrolle, PhD, ${ }^{7}$ Maria Pau Ginebra, PhD, ${ }^{8}$ \\ Carmen Bunu Panaitescu, MD, PhD, ${ }^{9}$ Enrique Gómez-Barrena, MD, PhD, ${ }^{10}$ Fabio Catani, MD, ${ }^{1}$ \\ Paolo Paolucci, MD, Jorge S. Burns, PhD, ${ }^{1, \dagger}$ and Massimo Dominici, MD ${ }^{1, \dagger}$
}

Successful preliminary studies have encouraged a more translational phase for stem cell research. Nevertheless, advances in the culture of human bone marrow-derived mesenchymal stromal/stem cells (hBM-MSC) and osteoconductive qualities of combined biomaterials can be undermined if necessary cell transportation procedures prove unviable. We aimed at evaluating the effect of transportation conditions on cell function, including the ability to form bone in vivo, using procedures suited to clinical application. hBM-MSC expanded in current Good Manufacturing Practice (cGMP) facilities (cGMP-hBM-MSC) to numbers suitable for therapy were transported overnight within syringes and subsequently tested for viability. Scaled-down experiments mimicking shipment for $18 \mathrm{~h}$ at $4^{\circ} \mathrm{C}$ tested the influence of three different clinical-grade transportation buffers $(0.9 \%$ saline alone or with $4 \%$ human serum albumin [HSA] from two independent sources) compared with cell maintenance medium. Cell viability after shipment was $>80 \%$ in all cases, enabling evaluation of (1) adhesion to plastic flasks and hydroxyapatite tricalcium phosphate osteoconductive biomaterial (HA/ $\beta$-TCP 3D scaffold); (2) proliferation rate; (3) ex vivo osteogenic differentiation in contexts of $2 \mathrm{D}$ monolayers on plastic and 3D HA/ $\beta$ TCP scaffolds; and (4) in vivo ectopic bone formation after subcutaneous implantation of cells with HA/ $\beta$-TCP scaffold into NOD/SCID mice. Von Kossa staining was used to assess ex vivo osteogenic differentiation in 3D cultures, providing a quantifiable test of 3D biomineralization ex vivo as a rapid, cost-effective potency assay. Near-equivalent capacities for cell survival, proliferation, and osteogenic differentiation were found for all transportation buffers. Moreover, cGMP-hBM-MSC transported from a production facility under clinical-grade conditions of $4 \% \mathrm{HSA}$ in $0.9 \%$ saline to a destination $18 \mathrm{~h}$ away showed prompt adhesion to HA/ $\beta$-TCP 3D scaffold and subsequent in vivo bone formation. A successfully validated transportation protocol extends the applicability of fresh stem cells involving multicentric trials for regenerative medicine.

\footnotetext{
${ }^{1}$ Laboratory of Cell Biology and Advanced Cancer Therapies, Department of Medical and Surgical Sciences for Children \& Adults, University Hospital of Modena and Reggio Emilia, Modena, Italy.

${ }^{2}$ Department of Internal Medicine and Oncology, University of Bari “A. Moro," Bari, Italy.

${ }^{3}$ Cell Factory, Fondazione IRCCS Ca' Granda Ospedale Maggiore Policlinico, Milano, Italy.

${ }^{4}$ EFS-Pyrénées-Méditerranée, Toulouse, France.

${ }^{5}$ UMR5273-U1031 STROMALab, CNRS, INSERM, Université Paul Sabatier Toulouse3, EFS, Toulouse, France.

${ }^{6}$ Institute of Clinical Transfusion Medicine and Immungenetics Ulm, German Red Cross Blood Transfusions Service and University of Ulm, Ulm, Germany.

${ }^{7}$ INSERM U957, Laboratory of Pathophysiology of Bone Resorption, Faculty of Medicine, University of Nantes, Nantes, France.

${ }^{8}$ Department of Materials Science and Metallurgical Engineering, Technical University of Catalonia, Barcelona, Spain.

${ }^{9}$ Victor Babes University of Medicine and Pharmacy, Timisoara, Romania.

${ }^{10}$ Servicio de Cirugía Ortopédica y Traumatología, Hospital La Paz-IdiPaz and Universidad Autónoma de Madrid, Madrid, Spain.

*Current affiliation: CSA21, Toulouse, France.

These authors contributed equally to this work.
} 


\section{Introduction}

$\mathbf{H}$ UMAN BONE MARROW-derived mesenchymal stromal/ stem cells (hBM-MSC) can be isolated and expanded ex vivo under current Good Manufacturing Practice (cGMP) conditions ${ }^{1}$ for clinical applications, including autologous treatment of large bone defects, ${ }^{2}$ usually combining cells with biocompatible bone-like scaffold biomaterials. ${ }^{3-7}$ To date, research has predominantly been focused on growth conditions for safe expansion of hBM-MSC ex vivo, with an emerging consensus that platelet lysate (PL) from whole bloodderived pooled platelet concentrates is a growth supplement of choice, ${ }^{8-12}$ with growth-promoting properties exceeding combinations of its individual active components PDGF-BB, bFGF, and TGF- $\beta 1^{13}$ and consistency improved by pooling. ${ }^{14}$

In certain circumstances, the specialized cell production facility may be distant from the operating theater, necessitating transportation of the cGMP cellular therapy product and current standards for short-term shipment between laboratories vary. ${ }^{15}$ Specifically, the inherent osteogenic differentiation potential of the hMSC should be maintained beyond all processes, including isolation from tissues, cell expansion, transportation, seeding on biomaterial, and implantation. However, there is relatively little data regarding the influence of transportation on the results of the preclinical studies, especially with regard to functional outcomes in vivo. Although cryopreserved hBM-MSC may retain good bone-forming potential, ${ }^{16,17}$ shipments of frozen cells would be impractical for operating theatre protocols involving short-term storage and prompt use. Furthermore, adverse reactions from cryoprotective reagents represent a complication, ${ }^{18}$ and freshly thawed hBM-MSC may have temporary impairment of function. ${ }^{19}$

With regard to nonfrozen cell transportation conditions, most studies assessed ex vivo viability and biomarker expression rather than in vivo function. ${ }^{20,21}$ It has been shown that hMSC kept under brief cold storage maintained boneforming potential, ${ }^{22}$ but the effects of storage and shipping under cGMP condition have not been evaluated. The viability of short-term liquid-stored hBM-MSC was enhanced by human serum albumin (HSA), ${ }^{20}$ but considerable differences between HSA batches from different manufacturers were noted. We, thus, sought to compare transport buffers with or without HSA, measuring their effects on cell viability, adhesion to the scaffold, and ex vivo osteogenic differentiation. Positive early indications of competent cell performance justified subsequent implantation of xenografts to test boneforming potential. Ultimately, our clinical-grade procedures for isolation, expansion, transportation, and seeding of cGMPhBM-MSC on osteoconductive biomaterial with prompt implantation preserved good bone-forming potential.

\section{Materials and Methods}

\section{Cell culture}

hBM-MSCs from cGMP facilities; Etablissement Français du Sang, Toulouse (France), Institute of Clinical Transfusion Medicine and Immunogenetics Ulm (Germany), and Cell Factory (Fondazione IRCCS Ca' Granda Ospedale Policlinico) in Milano (Italy) were isolated and expanded to single clinical doses of at least $100 \times 10^{6}$ cGMP-hBM-MSC. The two-step protocol for unprocessed bone marrow cells involved seeding at an initial density of 50,000 white blood cells $/ \mathrm{cm}^{2}$ in $300 \mathrm{~mL}$ complete medium in CellStack ${ }^{\mathrm{TM}}$ (Corning) tissue culture vessels using PL-based, animalserum free tissue culture medium. ${ }^{23}$ Informed consent from all donors conformed to the Declaration of Helsinki, and project approval by local ethical committees included testing of BM donors according to the guidelines for preparation of blood products.

cGMP-hBM-MSCs passaged only once (p1) were shipped as live cells in a transportation syringe on ice or as frozen vials on dry ice. On arrival, live cells were used immediately, and frozen cells were stored in liquid nitrogen until required. Thawed cells were seeded at $6 \times 10^{3}$ cells $/ \mathrm{cm}^{2}$ in T75 flasks (Greiner Bio-One) incubated at $37^{\circ} \mathrm{C}$ with $5 \%$ humidified $\mathrm{CO}_{2}$ using maintenance medium (MM) consisting of $\alpha$-minimum essential medium (MEM) without nucleosides (Gibco ${ }^{\circledR}$ Invitrogen), supplemented with 8\% PL, ${ }^{24} 1 \%$ L-Glutamine (Gibco Invitrogen), $1 \mathrm{UI} / \mathrm{mL}$ heparin (SigmaAldrich), and $10 \mu \mathrm{g} / \mathrm{mL}$ ciprofloxacin (HIKMA). The cGMPhBM-MSCs were replenished with fresh MM twice weekly and at $80-85 \%$ confluence, they were detached using trypsin $0.05 \%$ /EDTA $0.02 \%$ (PAA Laboratories) or TrypLE (Gibco Invitrogen). cGMP-hBM-MSCs were immunophenotypically and functionally characterized in the cGMP facilities ensuring high viability before shipping (data not shown).

\section{Scaffold biomaterial}

A biphasic composite calcium phosphate scaffold biomaterial made of $20 \%$ hydroxyapatite and $80 \% \quad \beta$-tri-calcium phosphate (HA/ $\beta-\mathrm{TCP})$ was supplied as granules of $1-2 \mathrm{~mm}$ diameter with an average pore size of $300 \mu \mathrm{m}$ and manufactured according to ISO-13485 certification (Biomatlante SA).

\section{Comparative analysis of transportation conditions}

To pragmatically compare transportation buffers in a controlled environment, p1 cGMP-hBM-MSC were thawed and expanded in $\mathrm{MM}$, harvested and re-suspended at $20 \times 10^{6}$ cells $/ \mathrm{mL}$ of transportation buffer in a $5 \mathrm{~mL}$ syringe with void air removed, and kept at $4^{\circ} \mathrm{C}$ for $18 \mathrm{~h}$, mimicking transportation from cGMP facility to hospital. The transportation buffers tested were MM (control), 0.9\% normal saline (NS) 308mOsm/L, and pH-7.0 (S.A.L.F. SpA; Laboratorio Farmacologico) with $4 \% \mathrm{v} / \mathrm{v}$ HSA or NS alone. The HSA concentration selected $(4 \% \mathrm{w} / \mathrm{v})$ was equivalent to $580 \mu \mathrm{M}$ representing a mid-range value of albumin in plasma that typically ranges from 510 to $750 \mu \mathrm{M} .{ }^{25}$ We compared HSA from two manufacturers: HSA\#1 (Kedrion) and HSA\#2 (CSL Behring). After the mimicked shipment, cells from the transportation syringe were portioned into aliquots for $e x$ vivo and in vivo assays (Fig. 1i-v). For full-scale shipment, $100 \times 10^{6}$ freshly harvested cGMP-hBM-MSC were washed in saline solution, suspended in $5 \mathrm{~mL}$ NS supplemented with $4 \%$ HSA solution, and packed in a sterile luer lock $20-\mathrm{mL}$ syringe (B. Braun). Cells were shipped within $18 \mathrm{~h}$ from Ulm to Nantes via overnight express courier.

\section{Viability}

Cell viability before and after transportation conditions was assessed by propidium iodide (PI; Sigma-Aldrich) uptake and quantified by flow cytometry. ${ }^{26}$ Briefly, $5 \times 10^{4}$ cells 


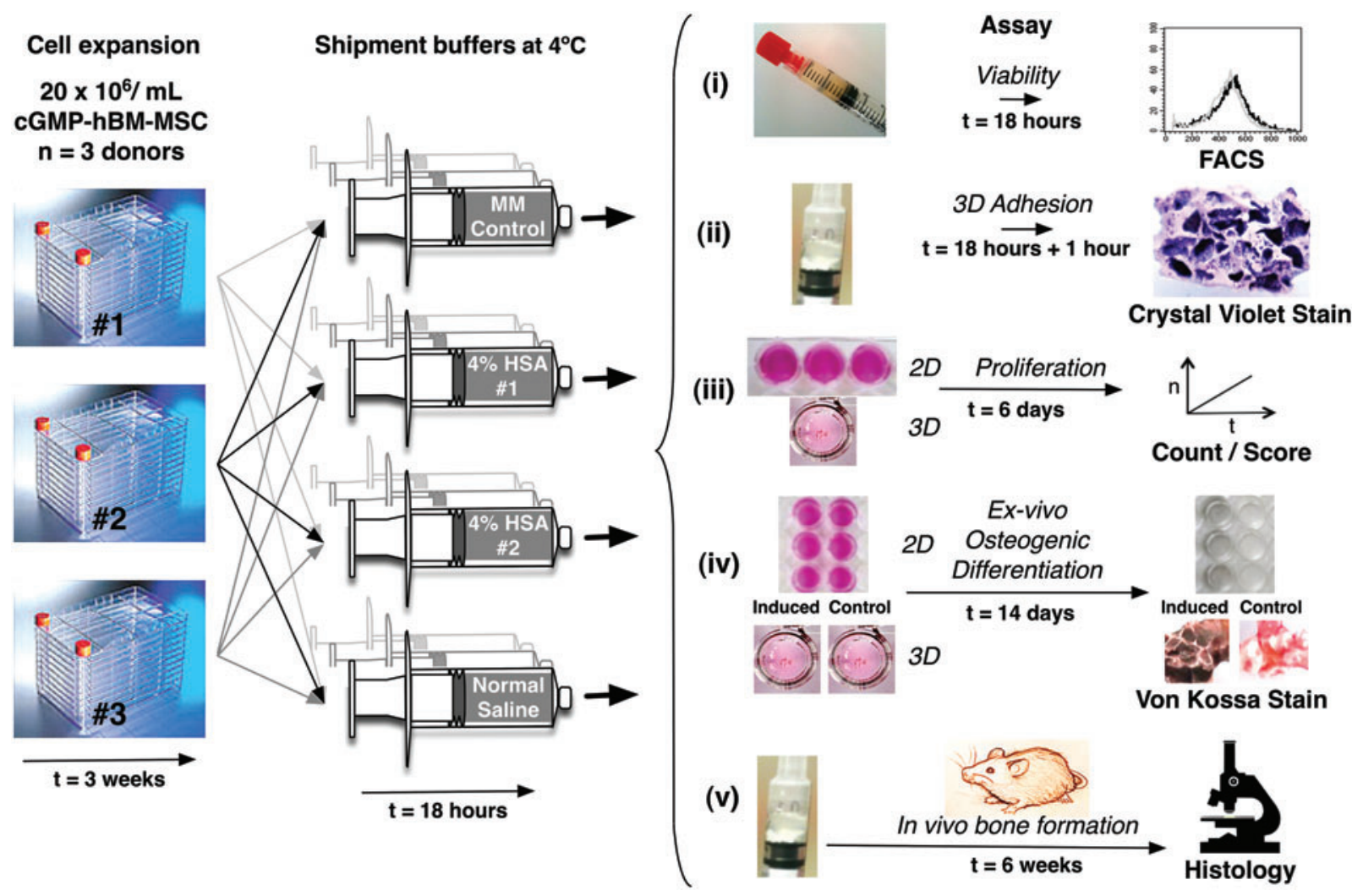

FIG. 1. Overview of experiments. hBM-MSC harvested from three independent donors at the cGMP facilities were harvested and maintained for $18 \mathrm{~h}$ at $4^{\circ} \mathrm{C}$ in syringes according to the $\mathrm{MM}$ control and three transportation conditions shown. After $18 \mathrm{~h}$, the cells from each syringe were analyzed to assess cell quality with regard to (i) viability; (ii) adhesion to a 3D scaffold; (iii) proliferation potential of cells kept as 2D monolayers or attached to 3D scaffold; (iv) ex vivo osteogenic differentiation potential of cells kept as 2D monolayers or cells attached to 3D scaffold; and (v) in vivo bone formation of cGMP-BM-MSC/HA/ $\beta$-TCP xenografts analyzed after 6 weeks by histology. hBM-MSC, human bone marrow-derived mesenchymal stromal/stem cells; cGMP, current Good Manufacturing Practice; HA/ $\beta$-TCP, $20 \%$ hydroxyapatite and $80 \%$ tri-calcium phosphate; MM, maintenance medium. Color images available online at www.liebertpub.com/tec

were incubated with $50 \mu \mathrm{g} / \mathrm{mL}$ PI for $30 \mathrm{~min}$ on ice-determining positivity with an FACSCalibur ${ }^{\mathrm{TM}}$ (BD Biosciences) instrument according to manufacturer's instructions.

\section{Cellular adhesion to 3D scaffold biomaterial}

cGMP-hBM-MSC adhesion to HA/ $\beta$-TCP scaffold was assayed by adding $8 \times 10^{5}$ cells in $100 \mu \mathrm{L}$ buffer within an upright 1-mL syringe preloaded with 20 scaffold granules ( $\approx 20 \mathrm{mg}$ ) (Fig. 1B) using an inverted sterile eppendorf tube lid during incubation at $37^{\circ} \mathrm{C}$ for $1 \mathrm{~h}$ in a humidified $5 \%-\mathrm{CO}_{2}$ incubator, whereby cells settled under gravity. Subsequently, the percentage of viable cells that remained suspended in the buffer was counted using 0.4\% Trypan blue dye (Biochrom). Scaffold-bound cells were stained using crystal violet buffer (Sigma-Aldrich) (0.04\% w/v in 100\% methanol) and visualized under bright field illumination at $2.5 \times$ magnification with an Axioskop-Observer-1 microscope (Zeiss) using an Axiocam camera and Axiovision-4.8.2 software to evaluate the percentage of scaffold surface area covered by blue stained cGMP-hBM-MSC. Samples were scored according to a predetermined incremental scale (Fig. 2) ranging from $0=$ no adherent cells, to $5=$ over $70 \%$ covered. An adhesion assay control used freshly detached cGMP-hBM-MSC without previous exposure to transportation conditions. All experiments were performed in triplicate.

\section{Three-dimensional scaffold repopulating potential of cGMP-hBM-MSC}

Colonization of the scaffold by cells stored at $4{ }^{\circ} \mathrm{C}$ in the various transportation buffers was measured by a one-step growth assay 6 days after keeping the scaffold under MM growth conditions at $37^{\circ} \mathrm{C}$ in a $5 \% \mathrm{CO}_{2}$ humidified incubator. For better details, $4 \times 10^{4}$ cGMP-hBM-MSC cells suspended in $5 \mu \mathrm{L}$ of transportation buffer were seeded per single scaffold granule in a 96-multiwell plate (MW) roundbottom ultra-low attachment (ULA) surface (Corning) and promptly incubated in a controlled atmosphere $\left(5 \% \mathrm{CO}_{2}\right.$, $37^{\circ} \mathrm{C}$ ) for $1 \mathrm{~h}$ before adding $100 \mu \mathrm{L}$ MM. Scaffold-bound cells were visualized using crystal violet stain and quantified according to the predetermined scoring reference (Fig. 2).

As a further control, the post-transportation proliferative potential of cGMP-hBM-MSC monolayers was assayed by seeding 6000 cells $/ \mathrm{cm}^{2}$ in MM into 12-well 12-MW (Greiner Bio-One) incubated at $37^{\circ} \mathrm{C}$ in a $5 \% \mathrm{CO}_{2}$ humidified 
FIG. 2. Adhesion score for cGMP-hBM-MSC on HA/ $\beta$-TCP scaffold. Representative photomicrographs for scaffold granules scored according to a predetermined scale by which a score of 0 represented no adhered cells and higher scores represented an increased percentage of granule surface coverage by crystal violet stained cells: $1=$ less than $10 \% ; 2=10$ $30 \% ; 3=30-50 \% ; 4=50-70 \%$; $5=$ over $70 \%$. The score range 0-2 was relevant for 1-h cell adhesion, and the score range 3-5 was relevant for cell coverage after 6 days. Scale bar $=100$ $\mu \mathrm{m}$. Color images available online at www.liebertpub.com/tec
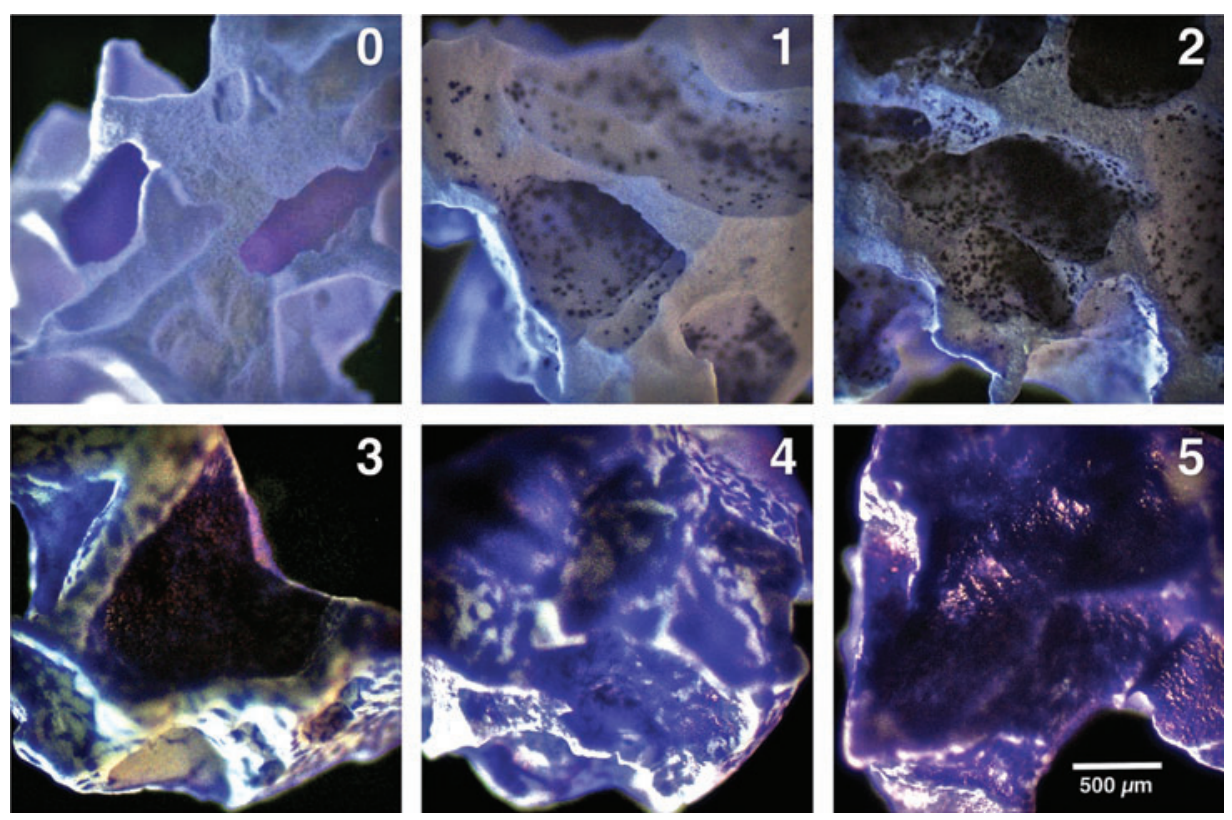

incubator. Phase-contrast photomicrographs were taken 1 and $24 \mathrm{~h}$ after seeding. MM was refreshed every 2-3 days, discarding nonadherent cells, and a total viable cell count after 6 days was used to calculate the fold increase in cell number. All experiments were performed in triplicate.

\section{Assessment of ex vivo osteogenic differentiation}

Osteogenic differentiation potential in 2D monolayer culture and on 3D scaffold was assessed as shown (Fig. 1D). For 2D assays, hBM-MSCs were seeded at $1 \times 10^{4} \mathrm{cell} / \mathrm{cm}^{2}$ in $\mathrm{MM}$ in $24-\mathrm{MW}$ plates. For 3D assays, $1.2 \times 10^{5} \mathrm{BM}-\mathrm{MSC}$ in $15 \mu \mathrm{L}$ of transportation buffer were seeded on three scaffold granules in 96-MW round-bottom ULA plates as described earlier for $1 \mathrm{~h}$ at $37^{\circ} \mathrm{C}, 5 \% \mathrm{CO}_{2}$ in a humidified atmosphere before adding $100 \mu \mathrm{L}$ MM. After 3 days' equilibration, MM was changed to osteogenic medium (OM), composed of $\alpha$ MEM-supplemented 8\% PL with $10 \mathrm{mM} \beta$-glycerophosphate (Sigma-Aldrich), $0.1 \mathrm{mM}$ ascorbic acid-2-phosphate (SigmaAldrich), and $10 \mathrm{nM}$ Dexamethasone (Sigma-Aldrich), plus addition of $100 \mathrm{ng} / \mathrm{mL}$ rhBMP-2 (Peprotech) from the 7 th day of induction.

After 2 weeks, osteogenically induced cultures in OM and parallel-control cultures in MM were fixed and used to compare three staining methods characterizing ex vivo osteogenic differentiation on 3D scaffolds: For alkaline phosphatase, cultures were fixed with acetone/citrate solution for $30 \mathrm{~s}$ and then rinsed gently with distilled water. After incubation with alkaline phosphatase staining solution (SigmaAldrich) for 15 min under dark, the cells were washed with distilled water. The acetone/citrate solution and alkaline phosphatase staining solutions were prepared as per manufacturer's instructions. Counterstaining with $0.04 \%$ crystal violet (Sigma-Aldrich) dissolved in water was as described. ${ }^{27}$ For alizarin red, the cultures were washed at room temperature in PBS, fixed on ice-cold methanol $(100 \% \mathrm{v} / \mathrm{v})$, washed with distilled water, and stained with alizarin red S $(1.5 \%$ $\mathrm{v} / \mathrm{v}, \mathrm{pH}-4.2$; Sigma-Aldrich) for $15 \mathrm{~min}$ to detect calcium precipitation. $^{28}$ Stained monolayers were visualized at $10 \times$ magnification with an inverted Axioskop-Observer-1 microscope (Zeiss). For von Kossa staining, samples were fixed in ice-cold methanol for $2 \mathrm{~min}$, then rinsed twice in distilled water, and were incubated under a ultraviolet (UV) lamp with silver nitrate (Sigma-Aldrich) in water. ${ }^{29}$ After two further washes in distilled water, 3D culture samples were counterstained with $0.02 \%$ nuclear fast red (Sigma-Aldrich) in distilled water, rinsed, and then washed in water for $10 \mathrm{~min}$. For each 2D sample, 10 high-power fields were observed using $10 \times$ magnification (Axioskop-Observer-1 inverted microscope; Zeiss); while for 3D cultures, $2.5 \times$ high-power fields were used to obtain three to six photomicrographs from each sample. Digitally recorded images analyzed by ImageJ software (National Institute of Health) selectively quantified dark positively stained areas of organic calcium deposits. Triplicate experiments were performed.

\section{In vivo bone-formation assay in immune-deficient mice}

After maintenance in transportation conditions for $18 \mathrm{~h}$ at $+4^{\circ} \mathrm{C}, 1.6 \times 10^{6} \mathrm{cGMP}-\mathrm{hBM}-\mathrm{MSC}$ in $80 \mu \mathrm{L}$ of buffer were gently added to $40 \mathrm{mg}$ of $1-2 \mathrm{~mm}$ diameter HA/ $\beta$-TCP granules ( $\approx 40$ granules) preloaded in an upright $1 \mathrm{~mL}$ tuberculin syringe. Before surgical subcutaneous implantation into dorsal sites of 8-week-old NOD.CB17 ${ }^{\text {-Prkdcscid/J }}$ mice (Charles River), ${ }^{30}$ cells were allowed to adhere to the scaffold in their respective transportation buffers for $1 \mathrm{~h}$ at $37^{\circ} \mathrm{C}$, in $5 \% \mathrm{CO}_{2}$ humidified incubator. As a control, cells grown in MM not subjected to shipment conditions were similarly implanted in vivo. Negative controls consisted of implantations using $40 \mathrm{mg} \mathrm{HA} / \beta-\mathrm{TCP}$ incubated with MM, but without cells. The Local Ethical Committee of the University of Modena and Reggio Emilia approved the protocols. Briefly, animals were anesthetized with $3.6 \%$ isofluorane (Abbott), and the dorsal skin was shaved and cleaned. Two incisions of $\approx 1 \mathrm{~cm}$ in length were performed on the opposite flanks of the back, a 3-cm-long pocket was formed by blunt dissection, and the xenograft was implanted. The 
incisions were sutured with ethicon vicryl rapide 35-0 (Johnson \& Johnson). Six weeks post-transplantation, xenografts recovered from sacrificed animals were processed for histological studies.

\section{Histology and immunohistochemistry}

Explanted specimens were fixed with $10 \%$ buffered formalin for 2 days, decalcified in PBS-buffered EDTA (15\%, pH 7.4; Carlo Erba) for 14 days, and then paraffin embedded, as similarly described for animal and human bone specimens. ${ }^{31,32}$ Cut sections ( $3 \mu \mathrm{m}$-thick) were deparaffinized and stained with hematoxylin and eosin (H\&E; Carlo Erba). To quantify bone formation, areas of osteogenesis were assessed as described. ${ }^{33}$ For each donor, triplicate sections were H\&E stained and visualized by an inverted microscope Axioskop (Zeiss) considering $10 \times$ high-power fields. Histological analyses considering bone matrix-containing embedded osteocytes were used to quantify the bone tissue percentage relative to the total area of tissue and scaffold on the slide.

Bone origin was detected by immunohistochemistry using human-specific osteocalcin and collagen 1A2 polyclonal antibodies. ${ }^{31}$ Paraffin sections (5- $\mu \mathrm{m}$ thick) were dehydrated and stained with mouse anti-human collagen type 1A2 (1:20; Novus Biological) and mouse anti-human osteocalcin (1:30; Abcam) using a goat anti-mouse biotinylated secondary $\mathrm{Ab}$ (1:200; Vector Laboratories) and an avidin-biotin-horseradish peroxidase detection system (Vector Laboratories). Antigen retrieval used proteinase $\mathrm{k}$ (Promega Corporation) for $30 \mathrm{~min}$ at room temperature, blocking nonspecific binding with $10 \%$ new-calf serum blocking reagent (Sigma-Aldrich). The primary antibody in $0.1 \%$ bovine serum albumin (SigmaAldrich) and $0.4 \%$ Triton-X (Sigma-Aldrich) was applied overnight. After Secondary Ab (Vector Laboratories) incubation and quenching, slides were incubated with Vectastain ABC (Vector Laboratories) as per manufacturer's instructions with color development using NovaRED (Vector Laboratories). Slides were counterstained with Harris hematoxylin (Bio Optica). Negative control specimens were stained with a mouse isotypic IgG primary Ab (Vector Laboratories). Stained slides were examined using a Zeiss Axioskop (Carl Zeiss) with either a $10 / 0.25 \mathrm{NA}$ or $40 / 0.6 \mathrm{NA}$ dry objective. Photomicrographs were acquired with an Axiocam-IcC3 color camera and Axiovision-4.8.2 software (Carl Zeiss).

\section{Statistical analysis}

All data collected were presented as means \pm standard error of the mean. Statistical analysis was performed using the paired Student's $t$-test. $p$-Values $<0.05$ were considered statistically significant.

\section{Results}

\section{Transportation buffers preserve fresh cGMP-hBM-MSC viability}

A direct comparison of four transport buffers with three independent donors cGMP-hBM-MSCs revealed that under control conditions using MM, cell death stained by PI was equivalent to $12.13 \% \pm 1.58 \%$ of the population (Fig. 3A). Transportation buffers invoked significantly more cell death than MM $(p<0.01)$, yet cell death remained below $20 \%$ without enhancement of cell viability from HSA (Fig. 3B).
A个
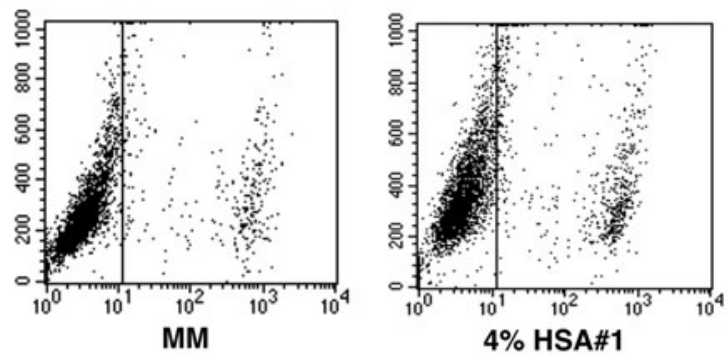

ఝु
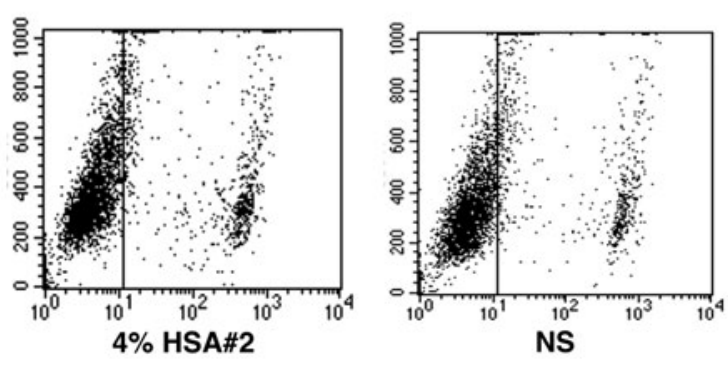

PI

B

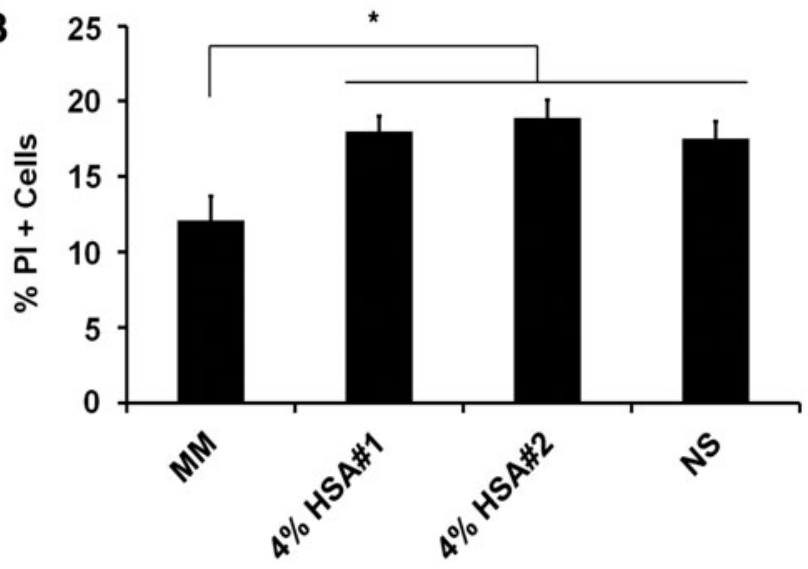

FIG. 3. Viability after transportation conditions. (A) Flow cytometric analysis of PI positivity plotted against SSC for cells maintained under different shipment conditions, including MM, and transportation buffers containing $4 \%$ HSA or only NS. (B) Histogram derived from $n=3$ donors indicating the percentage of PI-positive dead cells after incubation for $18 \mathrm{~h}$ under each transportation buffer condition. $\left({ }^{*} p<0.05\right)$. HAS, human serum albumin; PI, propidium iodide; SSC, side scatter; NS, normal saline.

Given these initial viability data, we explored the interaction of the cells with the 3D scaffold.

\section{cGMP-hBM-MSC promptly adhered to the $3 D$ scaffolds}

After applying cGMP-hBM-MSC to scaffold biomaterial for $1 \mathrm{~h}$ at $37^{\circ} \mathrm{C}$, cells shared two fractions: (1) nonadherent cells suspended in the shipment buffer and (2) scaffold surfacebound cells (Fig. 4A). When using MM control conditions, $19.8 \% \pm 5 \%$ of the cells were in fraction (1) (Fig. 4B). More nonadherent cells were found when using the transportation 
FIG. 4. Cell adhesion to a 3D scaffold under gravity for $1 \mathrm{~h}$. Photomicrograph of upright $1 \mathrm{~mL}$ syringe containing scaffold granules seeded with cells in $200 \mu \mathrm{L}$ of shipment buffer after $1 \mathrm{~h}$. (A) The solid and liquid phases were co-analyzed for $n=3$ donors in each of the four shipment buffers to determine (B) the percentage of viable (shaded columns) or nonviable (unshaded columns) nonadherent cells in the supernatant and (C) the scaffold cell adhesion score $\left({ }^{*} p\right.$, $\left.{ }^{* *} p,{ }^{\S} p<0.05\right)$. (D-I) Representative photomicrographs comparing (D) unstained scaffold; (E) crystal violet stained scaffold; (F-I) scaffolds stained after $1 \mathrm{~h}$ to show attachment of cells that had been kept for $18 \mathrm{~h}$ at $4^{\circ} \mathrm{C}$ in shipment buffers consisting of (F) MM; (G) saline with 4\% HSA\#1; and (H) saline with $4 \%$ HSA\#2, (I) NS. (D-I) Scale bar $=100 \mu \mathrm{m}$. Color images available online at www.liebertpub .com/tec
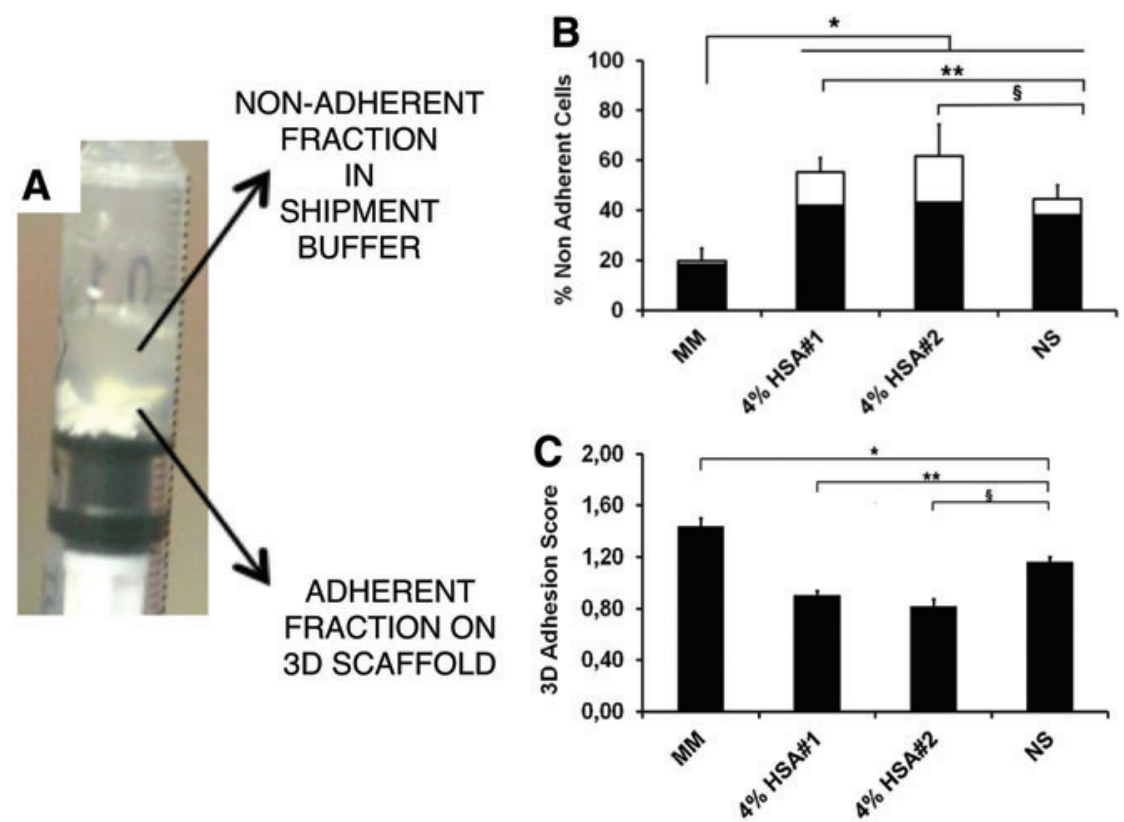

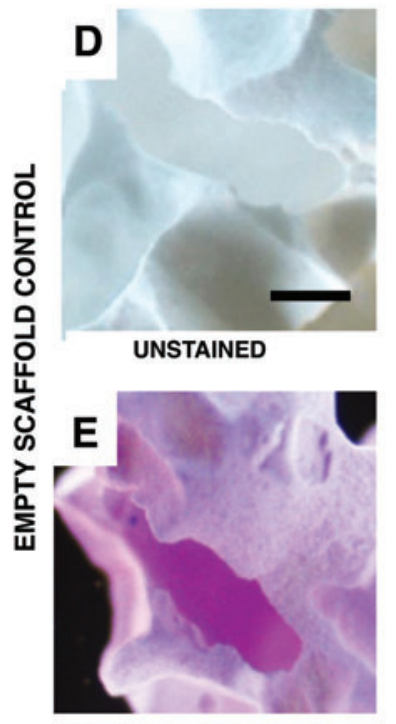

CRYSTAL VIOLET

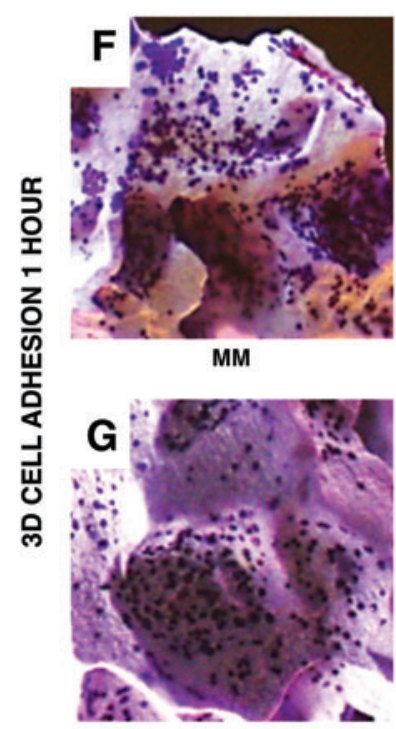

$4 \%$ HSA\#2

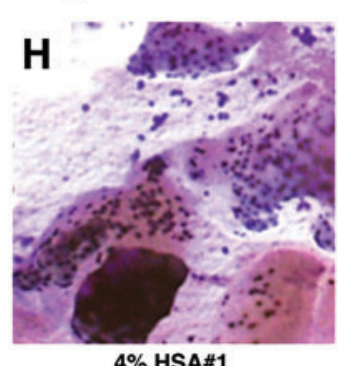

4\% HSA\#1

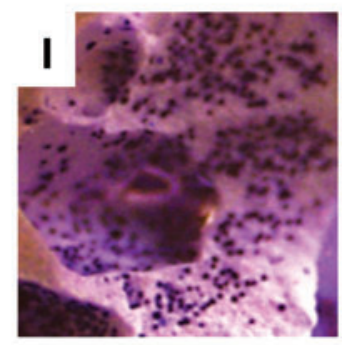

NS buffers versus $\mathrm{MM}(p<0.01)$; ranging from $55.3 \% \pm 5.8 \%$ to $61.7 \% \pm 12.7 \%$ when using HSA\#1 or HSA\#2, respectively, and $44.5 \% \pm 5.7 \%$ when using NS. The nonadherent cell viability after $1 \mathrm{~h}$ was highest for cells stored in MM $(90.3 \% \pm 1.9 \%)$. Notably, the corresponding nonadherent cell viability was significantly greater for the NS only transport buffer $(86.4 \% \pm 1.3 \%)$ than either NS $+4 \%$ HSA\#1 (76.2\% $\pm 3 \%$; $p<0.05)$ or NS $+4 \%$ HSA\#2 $(73.9 \% \pm 3.4 \% ; p<0.05)$.

The adhesion score was referenced to assess the fraction (2) viable cells stringently adhered to the 3D scaffold after $1 \mathrm{~h}$ of incubation and crystal violet staining. Under MM conditions, the adhesion score was $1.44 \pm 0.5$. Significantly less cell adhesion was observed with NS-only transport buffer (1.16 \pm 0.1 ; $p<0.01)$, nonetheless more than seen using either HSA\#1 $(0.91 \pm 0.1 ; p<0.01)$ or HSA\#2 $(0.82 \pm 0.1 ; p<0.05)$ (Fig. $4 \mathrm{C})$. Compared with the faint HA/ $\beta$-TCP scaffold background staining (Fig. 4D, E), dark blue-stained cells were clearly discernible for a reference-scale comparison. The average cell ad- hesion score obtained with HSA\#1 (Fig. 4C, H) was only $57 \%$ $(p<0.05)$ of that seen with MM (Fig. 4C, F), while the NS transportation buffer achieved $81 \%$ (Fig. $4 \mathrm{C}-\mathrm{I} ; p<0.01$ ) of the $\mathrm{MM}$ adhesion score. Thus, with regard to a prompt and robust cGMP-hBM-MSC adhesion capacity, NS transport buffer conditions met the metrics desired for an operating theater context.

\section{cGMP-hBM-MSCs proliferated in $2 D$ culture and efficiently repopulated $3 D$ scaffolds}

Beyond viability and adhesion, post-transportation condition cells showed equivalent proliferative potential when seeded as 2D monolayers, averaging a 13.5-fold population increase in 6 days (Fig. 5A). Similarly, all cGMP-hBM-MSC seeded on HA/ $\beta$-TCP granules colonize their surface. Control cells in MM reached a score of 3.32 \pm 04 , similarly achieved using HSA-based buffers, while cGMP-hBM-MSC stored in NS transportation buffer had lower scores (Fig. 5B; 

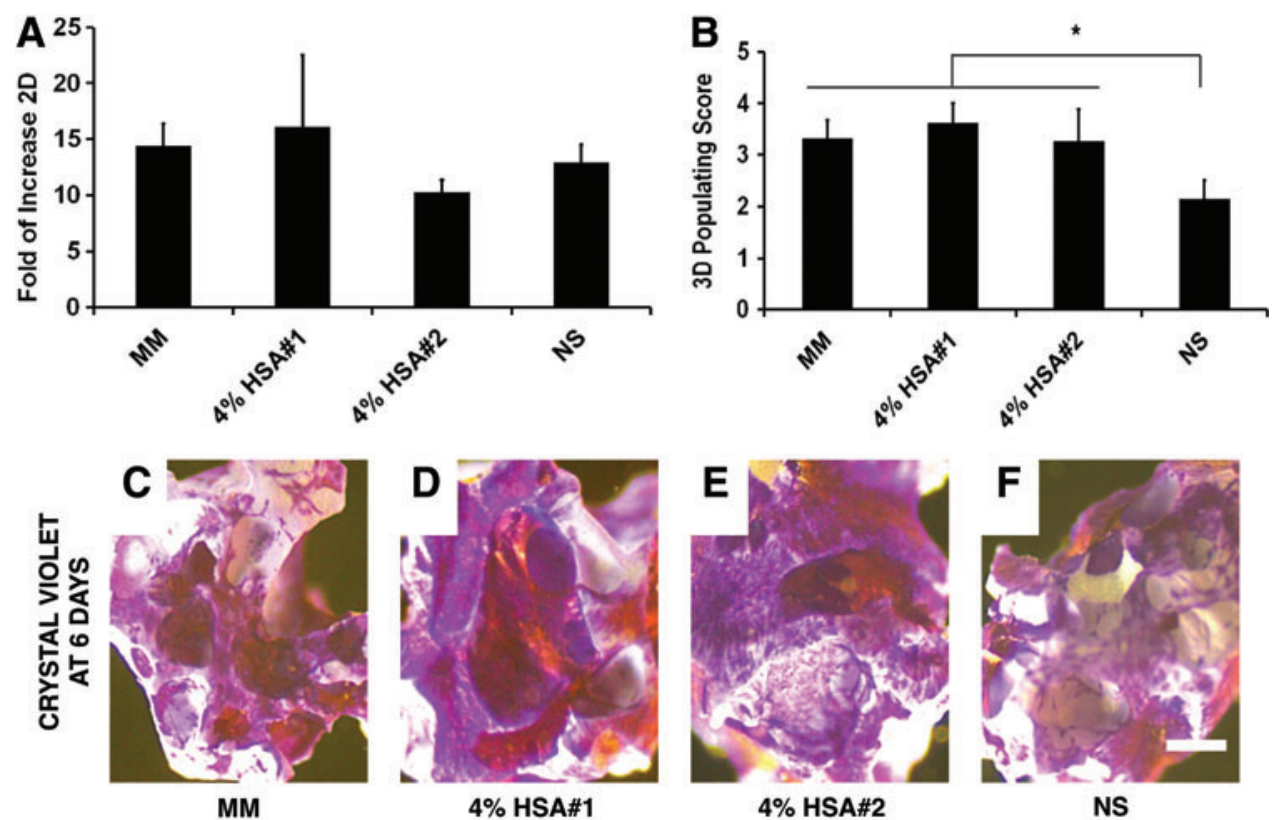

4\% HSA\#2

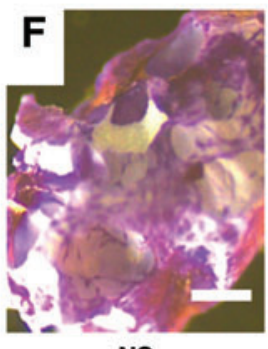

NS
FIG. 5. Proliferation potential of cells kept as 2D monolayers or attached to 3D scaffold. Histograms for the fold increase in cell number for one step time points determined for cells grown as (A) 2D monolayers on tissue culture plastic or (B) attached to the 3D scaffold. (C-F) Representative photomicrographs of scaffolds bearing crystal violet-stained hBMMSC after cells had been kept for $18 \mathrm{~h}$ at $4^{\circ} \mathrm{C}$ in the different transportation buffers indicated seeded onto the scaffold for $1 \mathrm{~h}$ and then cultured for 6 days in MM. Scale bar $=100 \mu \mathrm{m}$. Color images available online at www .liebertpub.com/tec
$2.14 \pm 0.4 ; p<0.05)$. Thus, proliferative potential was maintained after early adhesion regardless of the shipment buffer used with cells repopulating over $50 \%$ of the scaffold surface (adhesion score 2) after 6 days in culture (Fig. 5C-F).

\section{cGMP-hBM-MSC generated mineralized matrix on both plastic surface and $3 D$ scaffolds}

Extending 2D MSC-plastic monolayer ex vivo osteogenic potency assays to include consideration of 3D MSC-scaffold adhesion, we tested three histochemical stains for detecting the intrinsic osteogenic differentiation of 2D and 3D cultures.

Osteogenic matrix maturation-associated alkaline phosphatase staining was evidently more intense in differentiated cell monolayers regardless of transportation conditions (Fig. $6 \mathrm{~A}$, upper panel), but intense HA/ $\beta$-TCP scaffold background staining precluded proper evaluation of $3 \mathrm{D}$ cultures (Fig. 6B, upper panel). Alizarin red S staining of calcium-rich deposits, though significant in all monolayer cultures (Fig. $6 \mathrm{~A}$, middle panel), also suffered from high HA/ $\beta$-TCP scaffold background staining (Fig. 6B, middle panel). In contrast, von Kossa staining of calcium phosphate provided a clear black positive stain that was absent in control conditions (Fig. 6A, B lower panels), enabling clear threshold discrimination for image analysis software to semiautomate quantitation (Fig. 6B, lower panel inset). In 2D, von-Kossa-stained areas for osteogenically induced cGMPhBM-MSC in 2D were equivalent for all transport buffers, regardless of HSA, and marginally greater than for cells stored in MM $(p<0.04$; Fig. 6C). For 3D osteogenically induced cGMP-hBM-MSC, von Kossa stained an average HA/ $\beta$-TCP scaffold surface area of $17.6 \% \pm 2.2 \%$ for MM, similar to the NS-based transportation buffers, except for HSA\#2 having a reduced stained area of $9.7 \% \pm 1.9 \%(p<0.05$; Fig. $6 \mathrm{D})$. Notably, von Kossa also revealed inter-donor heterogeneity, with donor\#2 showing less scaffold surface area staining, $5.4 \% \pm 1.5 \%$, than the other two donors $(24.6 \% \pm$ $3.9 \%$ and $21.7 \pm 4.7 \%)(p<0.01$; Fig. $6 \mathrm{E}, \mathrm{F})$. Thus, it was possible to measure MSC mineralized matrix production in both 2D and 3D culture systems, providing a more comprehensive ex vivo assay.

\section{Transported cGMP-hBM-MSC with HA/ $\beta-T C P$ scaffolds generated ectopic bone in vivo}

An in vivo xenotransplant model using sub-cutaneously implanted cells and scaffold incontrovertibly tested the osteogenic potential of cGMP-hBM-MSC post-transportation conditions. HA/ $\beta$-TCP scaffold implanted without cells controlled for any inherent osteoinductive effects, revealing no extensive bone formation, rather loosely woven extracellular matrix and stromal cells surrounding the scaffold, sometimes aligned adjacent to the scaffold surface to resemble the surface-lining cells of normal bone tissue sections (Fig. 7A). Using HA/ $\beta$-TCP along with cGMP-hBM-MSC stored in transportation conditions, the scaffold surfaces were surrounded by large areas of pink-stained densely woven collagen fibrils typical of remodeled compact bone with interspersed lacunae containing mature bone osteocytes (Fig. 7B-E and inset). Moreover, the remodeled ectopic bone-enclosed regions were recognizable as hematopoietic territories (Fig. 7C, E and inset), a positive indication of good bone quality. ${ }^{34}$ In vivo bone formation at 6 weeks, though not significantly influenced by transportation conditions (not shown), showed inter-donor heterogeneity for the amount of bone formed. Bone areas of dense, pink-stained osteoid-containing osteocytes were observed in tissue sections from donors \#1 (28.5\% $\pm 4.1 \%)$ and \#3 $(22.8 \% \pm 4.5 \%$ ) (Fig. 7F, H, I), while donor \#2-derived MSC demonstrated less bone formation $(8.1 \% \pm 1.6 \%, p<0.01$; Fig. $7 \mathrm{G}, \mathrm{I})$, concordant with less ex vivo mineralization.

To verify the ontogeny of the bone-forming cells, the presence of human bone-related proteins was investigated. A Collagen 1A2 human-specific antibody stained osteocytes and bone-lining cells (Fig. 7J), with the latter also showing positivity for a human-specific osteocalcin antibody (Fig. 7K), thus verifying a robust in vivo bone-forming potential when cGMPhBM-MSC subjected to transportation conditions were combined with HA/ $\beta$-TCP osteoconductive scaffold. 
A
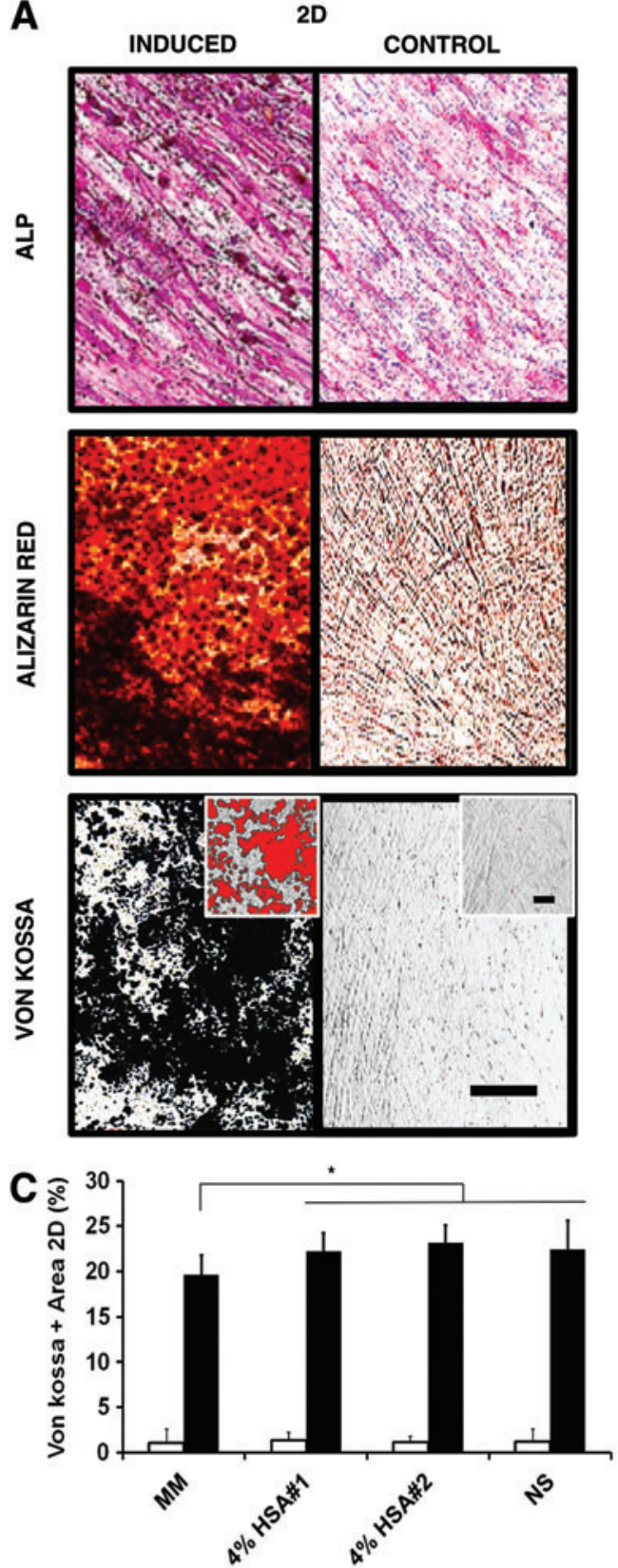

E

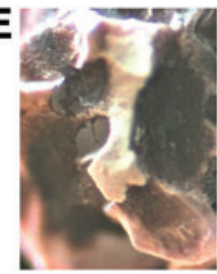

$\# 1$

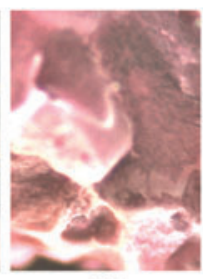

\#2

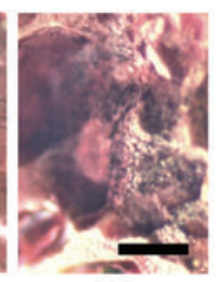

\#3

Donor

B
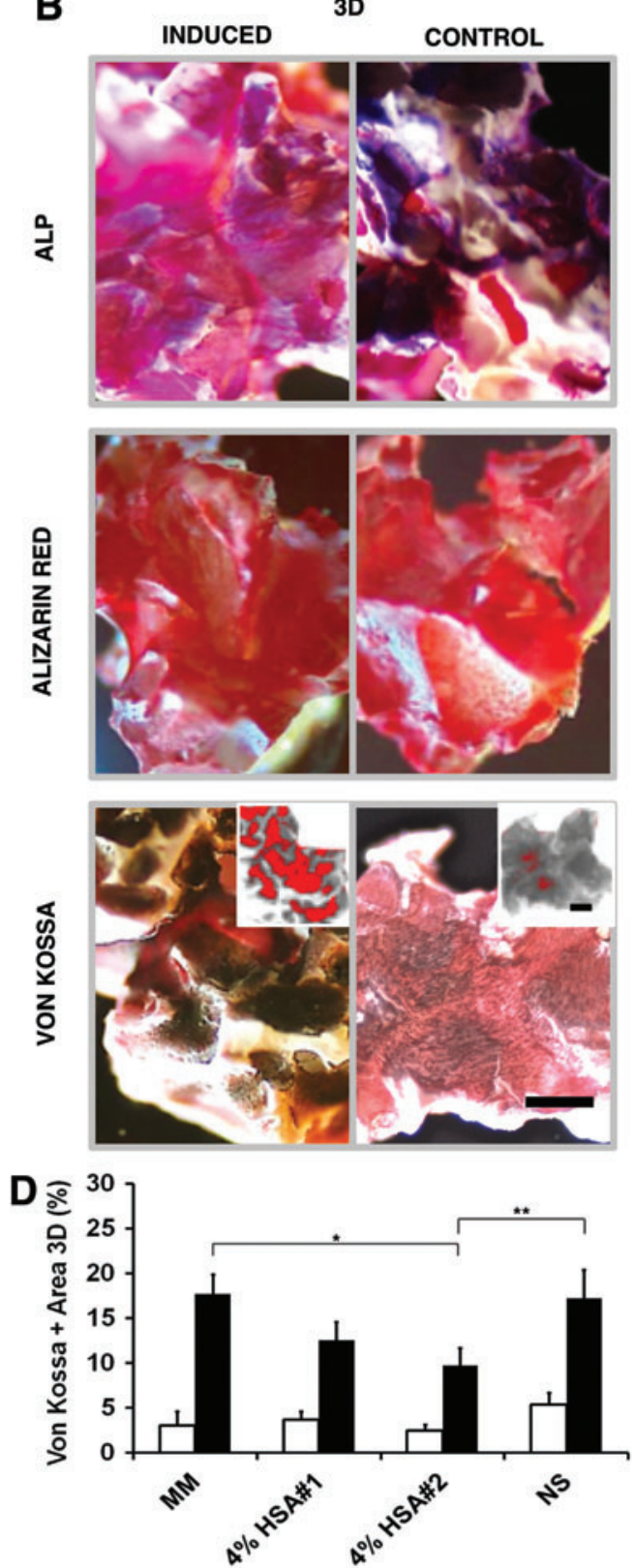

F

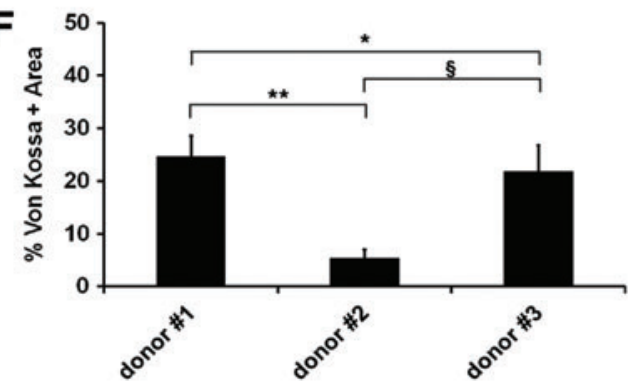

FIG. 6. Ex vivo osteogenic differentiation potential. Representative photomicrographs comparing three osteogenic differentiation-staining methods, namely staining for ALP or calcium deposits with alizarin red or von Kossa based methods. cGMP-hBM-MSC osteogenically induced for 2 weeks were compared with uninduced control cells grown as (A) 2D monolayers on plastic or (B) attached to 3D scaffolds. Lower panel inset images show von Kossa staining highlighted in red to indicate ImageJ software processed quantifiable thresholds. (C, D) Comparing different transportation buffer conditions, the histograms show the percentage of von Kossa-positive staining of undifferentiated control cells (unshaded columns) or osteogenically differentiated cells (shaded columns) grown as (C) 2D monolayers on plastic or (D) adhered to 3D scaffolds. (E) Photomicrographs of von Kossa-stained scaffolds, showing donor heterogeneity for cGMP-BM-MSC osteogenically differentiated after exposure to normal saline for $18 \mathrm{~h}$. (F) Histogram for percentage area of the scaffold surface positive for von Kossa staining as determined by ImageJ software $\left(* * *,{ }^{*} p<0.05\right)$. Scale bar $=100 \mu \mathrm{m}$. ALP, alkaline phosphatase. Color images available online at www.liebertpub.com/tec 

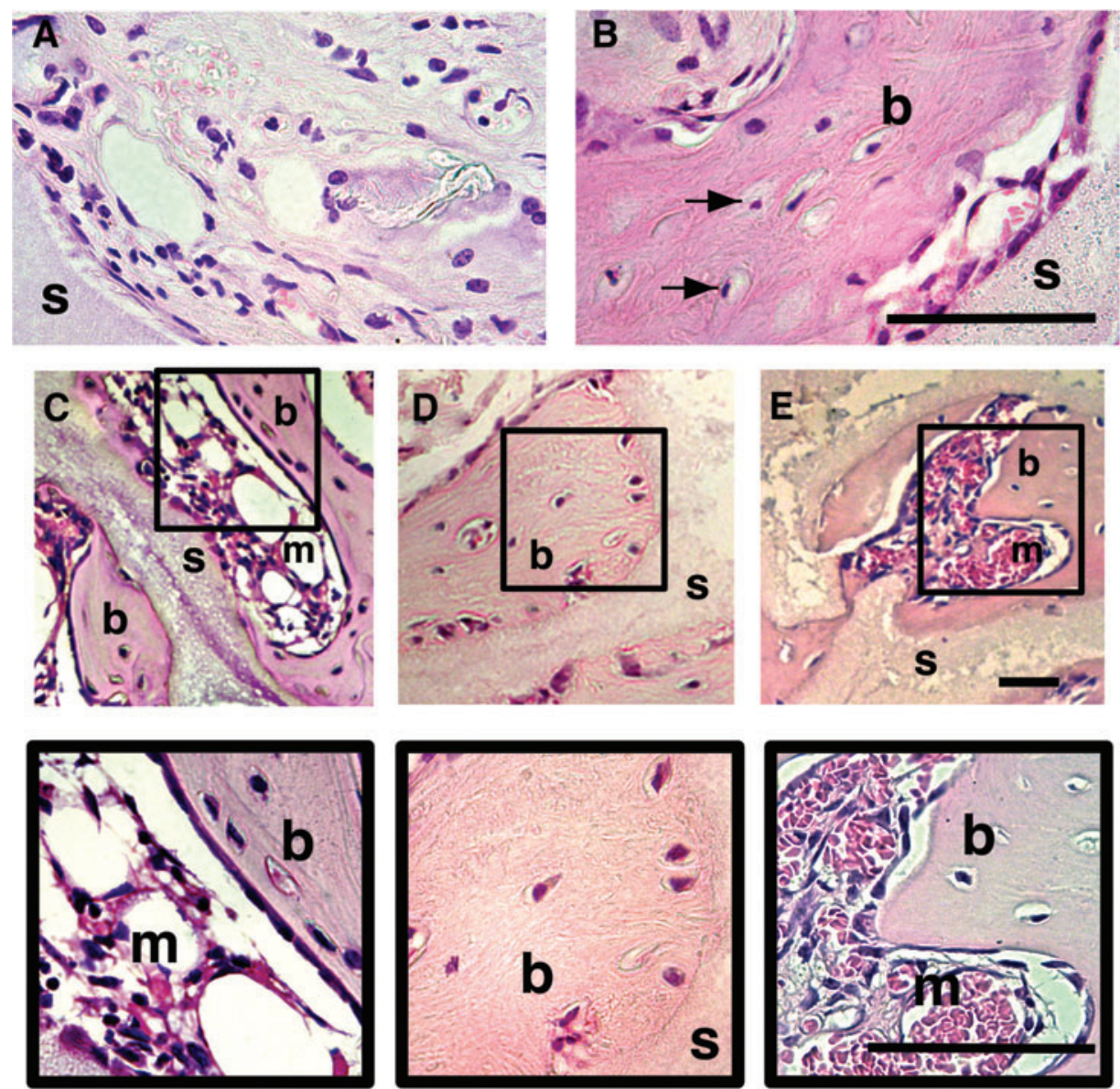

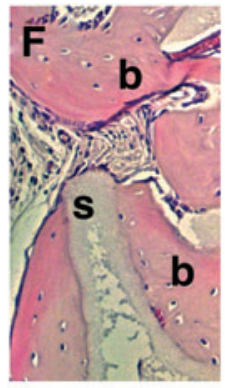

donor\#1

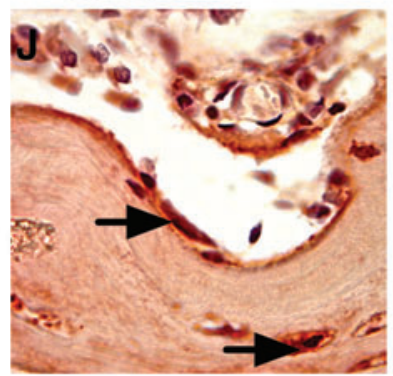

Collagen $1 \mathrm{A2}$

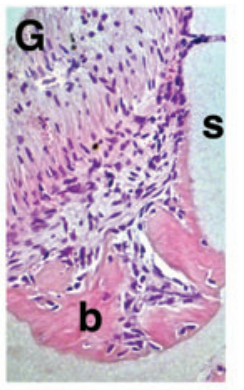

donor\#2

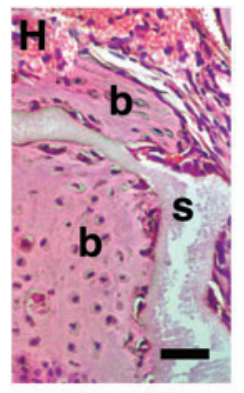

donor\#3
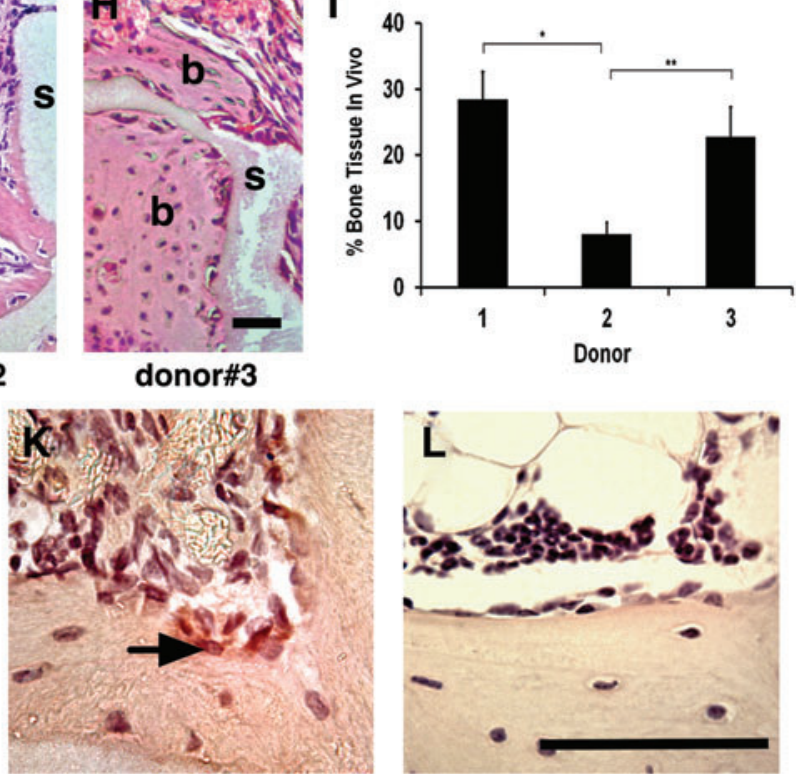

Osteocalcin

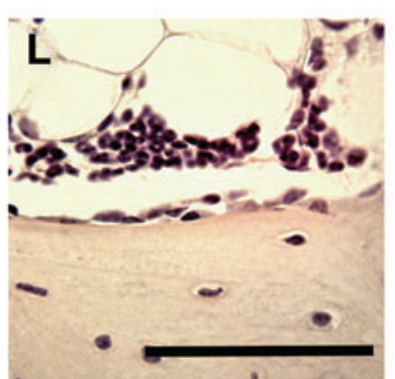

Negative Control
FIG. 7. In vivo bone-forming potential. Photomicrographs of decalcified paraffin-embedded sections under bright field illumination. (A) Comparing controls of scaffold (s) without cells versus (B) scaffold with cGMPhBM-MSC previously maintained in culture medium. Regions adjacent to the scaffold containing newly formed bone osteoid matrix (b). Osteocytes were observed within lacunae (arrow). (C-E) $10 \times$ and corresponding $40 \times$ area enlargements. Photomicrographs of tissue sections from scaffolds implanted with cGMP-BM-MSC kept under shipment buffers with (C) $4 \%$ HSA\#1; (D) $4 \%$ HSA\#2; or (E) NS. Osteoid bone (b) formed on the scaffold (s) surrounded marrow-like regions (m). Representative sections (FH) showed donor heterogeneity with regard to the relative amount of bone formed with (I) the corresponding histogram showing statistically significant differences $(* * * x<0.05)$. Scale bar $=100 \mu \mathrm{m}$. Immunostaining with NOVA red chromogenidentified cells lining the newly formed bone matrix osteoid positive for (J) collagen type (I) A2 and (K) osteocalcin in contrast to the unstained (L) control. Color images available online at www.liebertpub.com/tec

\section{Discussion}

From preclinical studies aimed at skeletal tissue regeneration, ${ }^{2}$ to clinical studies involving the transplantation of MSC with or without biomaterials, ${ }^{7}$ bone tissue engineering shows promise. Early trials indicate that the translation of

allogeneic and autologous cell therapeutics requires controlled manufacturing and delivery procedures. Given limited starting material for autologous hBM-MSC and the sub-optimal osteogenic performance of directly applied BM aspirates, ${ }^{35}$ ex vivo hMSC population expansion is currently a favored procedure adopted by cGMP cell processing 
facilities. Here, we aim at verifying conditions for safe MSC transportation to a distant hospital for immediate clinical application, thus overcoming a need to co-localize surgical facilities with specialized cell expansion laboratories, thereby widening therapeutic scope.

Transportation per se is a challenging procedure requiring careful control of cell density and temperature to maintain integrity while conforming to important safety constraints. Use of a clinically approved, nontoxic, and low-cell adhesion disposable syringe as a disposable shipment tool was in compliance with regulatory-body guidelines, simultaneously providing a convenient vessel for immediate application of the cells on arrival.

Considering clinical need for a minimal cell infusion volume, we tested shipment in a small volume using a relatively high cell density suitable for promptly combining the cells with the biocompatible scaffold material. Keeping a cellular product at high cell density in the same buffer for a prolonged time may foster undesirable metabolic shifts, weakening stem cell performance. ${ }^{36}$ However, hBM-MSC primary cultures may retain osteogenic functions more consistently when grown as dense aggregates with higher expression of alkaline phosphatase than dispersed single cells. ${ }^{37}$ Furthermore, hBM-MSC ordinarily reside as cell aggregates in vivo, and MSC were well maintained as dense cell aggregates in bioreactors. ${ }^{38,39}$ Under high cell density conditions in saline solution for $18 \mathrm{~h}$, the hBM-MSC may advantageously undergo a mild stress similar to hypoxic preconditioning, which could improve the regenerative capacity of hBM-MSC. ${ }^{40}$

Previous studies have indicated that cold storage of peripheral blood progenitor cells at $4^{\circ} \mathrm{C}$ for periods of approximately $96 \mathrm{~h}$ was significantly better for sustaining viability than higher ambient temperatures. ${ }^{41}$ This can also be said for hMSC viability, ${ }^{20}$ which reportedly fell to $81 \%$ after $24 \mathrm{~h}$ at $4^{\circ} \mathrm{C}$ but was only $70 \%$ at $24^{\circ} \mathrm{C}$ and $62 \%$ at $37^{\circ} \mathrm{C}^{22}$ thus from the outset, we chose to maintain shipment conditions at $4^{\circ} \mathrm{C}$. Unlike this previous study, our cells originated in medium containing human PL rather than bovine serum; however, we also observed a $20 \%$ loss of viability after storing cGMP-hBM-MSC at low temperature for $18 \mathrm{~h}$. With some concern for such storage-associated losses, it was important to explore the osteogenic function of the surviving cells.

Bioengineering modifications to scaffolds for enhanced bone formation is a rapidly evolving field, ${ }^{42-44}$ however, for clinical-grade consistency throughout our procedures and comparison with previous studies, ${ }^{45-47,34}$ we favored use of $\mathrm{HA} / \beta$-TCP scaffold to test cell attachment as an early indicator of cell function. HA/ $\beta$-TCP scaffold is a bioactive material, by which ion exchange reactions with surrounding body fluids form a biologically active carbonate apatite surface layer, equivalent to the mineral phase in bone, promoting collagen and mineral deposition from cells grown on the scaffold surface in vivo. ${ }^{46}$ The interaction between implant material and osteogenic cells contributes to clinical success, and hBM-MSC show strong affinity for calcium phosphate scaffolds that are consequently highly osseoconductive. $^{48,49}$

We tested a "field scenario" that introduced the time constraints of an operating theater, by which cells needed to be seeded onto the scaffold for just $1 \mathrm{~h}$ before implantation.
Impens et al. noted in cell-adhesion studies that although half the cells adhered to the biomaterial within $1 \mathrm{~h}$, the plateau of maximum cell adhesion was reached after $4 \mathrm{~h} .{ }^{50}$ We also observed nonadhered viable cells in the supernatant after $1 \mathrm{~h}$, but a 4-h adhesion period was deemed to be impractical for surgical procedures. For the in vivo bone-formation studies, the scaffold was implanted with accompanying supernatant; so feasibly, some cells could subsequently attach to the scaffold postimplantation or, nonetheless, contribute to the engraftment as nonattached cells. Considering the spatial uniformity of cells throughout the scaffold matrix, ${ }^{48}$ it was important to determine whether passive rather than dynamic loading procedures sufficed for an efficient bone-forming outcome. For our chosen scaffold/cell ratios, microscopic analysis revealed broadly distributed stained cells on the seeded scaffold after $1 \mathrm{~h}$. Uncomplicated loading under gravity was advantageously convenient for procedures within an operating theater.

In controls using MM, approximately $75 \%$ of the cells adhered to the scaffold within $1 \mathrm{~h}$; whereas using transport buffers adhesion efficiency was about 50\%. For HSAcontaining transport buffer, our choice of albumin concentration reflected observations that $4 \% \mathrm{w} / \mathrm{v}$ HSA was more effective than $3 \%$ or lower doses for inhibiting human endothelial cell apoptosis ${ }^{51}$ and preliminary data that higher HSA concentrations ( $10 \%$ or $20 \%$ ) reduced cell attachment to the $\beta$-TCP scaffold within $1 \mathrm{~h}$ (data not shown, Rojewski et al., in preparation). Notably, addition of just $4 \%$ HSA to the saline transport buffer already led to a small yet significant reduction in the 1-h cell adhesion score and increased the proportion of nonadhered cells, with one HSA source, in particular increasing the number of dead floating cells. This was contrary to expectation, as albumin, a nonglycosylated, negatively charged protein abundant in plasma, can beneficially maintain colloid osmotic pressure in plasma and sequester hormones, fatty acids, and metabolites having antiinflammatory activity. ${ }^{52}$ In addition, HSA enhanced cell viability in primary cultures of neurons due to ascribed oxygen-scavenging activities, ${ }^{53}$ and albumin-associated lipids positively influenced stem cell self-renewal. ${ }^{54}$ Thus, our finding was surprising given that HSA could be expected to provide a protective effect. However, HSA may simply prevent nonspecific adsorption of dead cells on culture vessel surfaces, artefactually allowing more dead cells to be counted. Alternatively, it is possible that co-presenting cells with HSA in solution, which is readily adsorbed onto HA composites $^{55}$ competetively interfered with cell attachment to the scaffold surface, disrupting anchorage-dependent integrin-mediated survival signals needed to prevent anoikis. ${ }^{56,57}$ Similarly, Lane et al. also reported that in the context of hMSC in suspension, the effects of HSA from different sources varied considerably and could reduce cell viability. ${ }^{20}$ Notably, although coating mineralized human bone allografts with freeze-dried HSA improved the adherence and proliferation of hBM-MSC, precoating with aqueous HSA was less effective. ${ }^{58}$ In the context of our protocol, copresenting aqueous HSA with cells onto fresh scaffolds may have caused competitive binding interference rather than enhanced adhesion. However, after 6 days ex vivo, the scaffold surface area covered by cells was greater when HSA was present; thus, over time, the beneficial effects of HSA in protecting cell functions may have predominated. Indeed, 
further studies would be needed to determine the molecular mechanisms underlying this observation.

With regard to testing the cGMP-hBM-MSC function of osteogenic differentiation, we obtained data from 2D and 3D cell culture contexts with the overall conclusion that transportation buffer differences were less apparent in 2D assays than in 3D assays. Assessment of osteogenic differentiation using alkaline phosphatase-specific or calcium-specific alizarin red $S$ staining methods proved impractical due to a high background stain in unseeded scaffolds. Nonetheless, the differentiation-specific von Kossa staining method worked well, with very low background staining of unseeded scaffolds. The dark von Kossa staining of mineralized cells after osteogenic differentiation of the cells that had been maintained for $18 \mathrm{~h}$ in saline-based transportation buffers was equivalent to that of control cells in MM. Notably, for unseeded scaffolds, the low von Kossa background staining was very different from the relatively strong alizarin red S staining of the scaffold. This seemed counterintuitive, as the high calcium concentration of the HA/ $\beta$-TCP scaffold might be expected to cause a high background stain in both cases. However, the two mineralization-staining methods react with the target calcium molecules differently. Alizarin red S impartially reacts with calcium via its sulfonic acid and/or $\mathrm{OH}$ groups to form a salt of a water-insoluble dye that selectively stains calcium deposits at $\mathrm{pH} \approx 9 .{ }^{28}$ In the von Kossa reaction, silver ions replace tissue calcium bound to phosphates, with subsequent visualization of silver ions by hydroquinone reduction to metallic silver. Puchtler et al. experimentally confirmed differences that von Kossa himself highlighted between the yellow stain of silver nitrate reacting with pure calcium phosphates versus black deposits in tissues, implying that the blackening of the silver salt-protein mixture was limited to a protein component. ${ }^{29}$ Our finding, that the black von Kossa reaction enhanced the signal-to-noise ratio for scaffolds coated with the osteogenically differentiated cells, supported the view that the black stain, long considered diagnostic for calcium salts (phosphates and carbonates), is more likely an organically induced by-product that, nonetheless, reflects a high local calcium concentration.

Given that ex vivo von Kossa staining need not correlate with bone-forming potential, ${ }^{59}$ the ultimate test for cGMPhBM-MSC osteogenic function was to perform an in vivo bone formation assay. ${ }^{45}$ Notably, we successfully obtained bone formation under procedures consistently appropriate for a clinical setting, and the cGMP-hBM-MSC were used either directly after experiments that compared suspension storage at $4^{\circ} \mathrm{C}$ with different transportation buffers or directly after a genuine shipment using full-scale conditions (data not shown, Brennan et al., in preparation). Others have already addressed the question of whether it would be beneficial to preincubate the cells with osteogenic factors before implantation. For the substantial majority of hBMMSC strains cultured over 15 years, continuous exposure to osteogenic differentiation factors such as dexamethasone or ascorbic acid did not increase subsequent bone formation under circumstances in which cells were implanted after an equivalent adhesion to scaffold period of merely $90 \mathrm{~min}$, emphasizing no need for a potentially inconvenient prior osteogenic induction of transplanted hBM-MSC. ${ }^{34}$

In addition to bone formation in terms of dense pinkstained osteoid harboring osteocytes in lacunae, we were re- assured that the transplanted hBM-MSC were able to support host hematopoietic territories. Thus, despite exposure to shipment conditions, the ectopically implanted cGMP-hBMMSC retained a phenotype of bona fide multipotent skeletal stem cells with establishment of stroma and marrow-like cell populations alongside the new bone matrix. ${ }^{33}$

An Occam's razor reductionist approach would suggest that, since HSA had little beneficial influence on ultimate outcome, $0.9 \% \mathrm{NS}$ alone may suffice for cell shipment and bone formation in vivo and could be recommended as the transport medium of choice. However, the present study indicated potential cell loss associated with the key steps of cell transportation and predelivery attachment to the scaffold, with an estimate that only $50 \%$ of the initial cell number shipped overnight actually ended up attached to the scaffold at the time of implantation. There may be a compromise to be reached between procedural cell loss and maintenance of cell viability, as alternative shipment methods and more elaborate buffer formulations may introduce unwanted variability and additional safety concerns. Nonetheless, alternative procedures may enhance cell survival ${ }^{60}$ and efficiency, leading to equivalent transplantation outcomes from fewer cells. Although the sample size of the present study was small, it was noteworthy that the inter-donor heterogeneity in osteogenic differentiation revealed by von Kossa staining of cells on 3D scaffolds correlated well with the subsequent inter-donor heterogeneity in bone formation. Our cost-effective test of shipping conditions, including quantifiable potency assay of 3D cell attachment and biomineralization ex vivo, may serve as a platform to explore procedures that further improve cGMP-hBM-MSC-mediated therapy. Principally, our clinically compliant experiments provided proof of concept for in vivo bone formation from shipped cells, broadening the scope for use of centrally produced cGMP-hBM-MSC in regenerative medicine involving multicentric clinical trials.

\section{Acknowledgments}

This work was supported in part by the European Commission Seventh Framework Program (FP7/2007-2013) (grant no. 241879), through the REBORNE project, the Italian Ministry of Health "Bando Cellule Staminali 2008" (M.D., P.P.), Regione Emilia Romagna (P.P., M.D.), and the Associazione ASEOP (P.P.). The authors are thankful to Flavia Parise and Renata Battini for their constant support in preclinical investigation studies.

\section{Disclosure Statement}

The authors do not have direct financial relations with the trademarks mentioned here.

\section{References}

1. Sensebe, L., Bourin, P., and Tarte, K. Good manufacturing practices production of mesenchymal stem/stromal cells. Hum Gene Ther 22, 19, 2011.

2. Quarto, R., Mastrogiacomo, M., Cancedda, R., Kutepov, S.M., Mukhachev, V., Lavroukov, A., Kon, E., and Marcacci, M. Repair of large bone defects with the use of autologous bone marrow stromal cells. N Engl J Med 344, 385, 2001.

3. Bruder, S.P., Kurth, A.A., Shea, M., Hayes, W.C., Jaiswal, N., and Kadiyala, S. Bone regeneration by implantation of pu- 
rified, culture-expanded human mesenchymal stem cells. J Orthop Res 16, 155, 1998.

4. Livingston, T.L., Gordon, S., Archambault, M., Kadiyala, S., McIntosh, K., Smith, A., and Peter, S.J. Mesenchymal stem cells combined with biphasic calcium phosphate ceramics promote bone regeneration. J Mater Sci Mater Med 14, 211, 2003.

5. Tilley, S., Bolland, B.J., Partridge, K., New, A.M., Latham, J.M., Dunlop, D.G., and Oreffo, R.O. Taking tissueengineering principles into theater: augmentation of impacted allograft with human bone marrow stromal cells. Regen Med 1, 685, 2006.

6. Dawson, J.I., and Oreffo, R.O. Bridging the regeneration gap: stem cells, biomaterials and clinical translation in bone tissue engineering. Arch Biochem Biophys 473, 124, 2008.

7. Ciapetti, G., Granchi, D., and Baldini, N. The combined use of mesenchymal stromal cells and scaffolds for bone repair. Curr Pharm Des 18, 1796, 2012.

8. Doucet, C., Ernou, I., Zhang, Y., Llense, J.R., Begot, L., Holy, X., and Lataillade, J.J. Platelet lysates promote mesenchymal stem cell expansion: a safety substitute for animal serum in cell-based therapy applications. J Cell Physiol 205, 228, 2005.

9. Vogel, J.P., Szalay, K., Geiger, F., Kramer, M., Richter, W., and Kasten, P. Platelet-rich plasma improves expansion of human mesenchymal stem cells and retains differentiation capacity and in vivo bone formation in calcium phosphate ceramics. Platelets 17, 462, 2006.

10. Schallmoser, K., Rohde, E., Bartmann, C., Obenauf, A.C., Reinisch, A., and Strunk, D. Platelet-derived growth factors for GMP-compliant propagation of mesenchymal stromal cells. Biomed Mater Eng 19, 271, 2009.

11. Xia, W., Li, H., Wang, Z., Xu, R., Fu, Y., Zhang, X., Ye, X., Huang, Y., Xiang, A.P., and Yu, W. Human platelet lysate supports ex vivo expansion and enhances osteogenic differentiation of human bone marrow-derived mesenchymal stem cells. Cell Biol Int 35, 639, 2011.

12. Bernardo, M.E., Cometa, A.M., Pagliara, D., Vinti, L., Rossi, F., Cristantielli, R., Palumbo, G., and Locatelli, F. Ex vivo expansion of mesenchymal stromal cells. Best Pract Res Clin Haematol 24, 73, 2011.

13. Fekete, N., Gadelorge, M., Furst, D., Maurer, C., Dausend, J., Fleury-Cappellesso, S., Mailander, V., Lotfi, R., Ignatius, A., Sensebe, L., Bourin, P., Schrezenmeier, H., and Rojewski, M.T. Platelet lysate from whole blood-derived pooled platelet concentrates and apheresis-derived platelet concentrates for the isolation and expansion of human bone marrow mesenchymal stromal cells: production process, content and identification of active components. Cytotherapy 14, 540, 2012.

14. Cho, H.S., Song, I.H., Park, S.Y., Sung, M.C., Ahn, M.W., and Song, K.E. Individual variation in growth factor concentrations in platelet-rich plasma and its influence on human mesenchymal stem cells. Korean J Lab Med 31, 212, 2011.

15. Pamphilon, D.H., Selogie, E., and Szczepiorkowski, Z.M. Transportation of cellular therapy products: report of a survey by the cellular therapies team of the Biomedical Excellence for Safer Transfusion (BEST) collaborative. Vox Sang 99, 168, 2010.

16. Yoshikawa, T., Nakajima, H., Takakura, Y., and Nonomura, A. Osteogenesis with cryopreserved marrow mesenchymal cells. Tissue Eng 11, 152, 2005.

17. Liu, G., Shu, C., Cui, L., Liu, W., and Cao, Y. Tissueengineered bone formation with cryopreserved human bone marrow mesenchymal stem cells. Cryobiology 56, 209, 2008.

18. Hunt, C.J. Cryopreservation of human stem cells for clinical application: a review. Transfus Med Hemother 38, 107, 2011.
19. Francois, M., Copland, I.B., Yuan, S., Romieu-Mourez, R., Waller, E.K., and Galipeau, J. Cryopreserved mesenchymal stromal cells display impaired immunosuppressive properties as a result of heat-shock response and impaired interferon-gamma licensing. Cytotherapy 14, 147, 2012.

20. Lane, T.A., Garls, D., Mackintosh, E., Kohli, S., and Cramer, S.C. Liquid storage of marrow stromal cells. Transfusion 49 , 1471, 2009.

21. Nikolaev, N.I., Liu, Y., Hussein, H., and Williams, D.J. The sensitivity of human mesenchymal stem cells to vibration and cold storage conditions representative of cold transportation. J R Soc Interface 9, 2503, 2012.

22. Muraki, K., Hirose, M., Kotobuki, N., Kato, Y., Machida, H., Takakura, Y., and Ohgushi, H. Assessment of viability and osteogenic ability of human mesenchymal stem cells after being stored in suspension for clinical transplantation. Tissue Eng 12, 1711, 2006.

23. Fekete, N., Rojewski, M.T., Furst, D., Kreja, L., Ignatius, A., Dausend, J., and Schrezenmeier, H. GMP-compliant isolation and large-scale expansion of bone marrow-derived MSC. PLoS One 7, e43255, 2012.

24. Schrezenmeier, H., and Seifried, E. Buffy-coat-derived pooled platelet concentrates and apheresis platelet concentrates: which product type should be preferred? Vox Sang 99, 1, 2010.

25. Dingari, N.C., Horowitz, G.L., Kang, J.W., Dasari, R.R., and Barman, I. Raman spectroscopy provides a powerful diagnostic tool for accurate determination of albumin glycation. PLoS One 7, e32406, 2012.

26. Ross, D.D., Joneckis, C.C., Ordonez, J.V., Sisk, A.M., Wu, R.K., Hamburger, A.W.N.R.E., and Nora, R.E. Estimation of cell survival by flow cytometric quantification of fluorescein diacetate/propidium iodide viable cell number. Cancer Res 49, 3776, 1989.

27. Wiedmann-Al-Ahmad, M., Gutwald, R., Lauer, G., Hubner, U., and Schmelzeisen, R. How to optimize seeding and culturing of human osteoblast-like cells on various biomaterials. Biomaterials 23, 3319, 2002.

28. Puchtler, H., Meloan, S.N., and Terry, M.S. On the history and mechanism of alizarin and alizarin red S stains for calcium. J Histochem Cytochem 17, 110, 1969.

29. Puchtler, H., and Meloan, S.N. Demonstration of phosphates in calcium deposits: a modification of von Kossa's reaction. Histochemistry 56, 177, 1978.

30. Abdallah, B.M., Ditzel, N., and Kassem, M. Assessment of bone formation capacity using in vivo transplantation assays: procedure and tissue analysis. Methods Mol Biol 455, 89, 2008.

31. Dominici, M., Rasini, V., Bussolari, R., Chen, X., Hofmann, T.J., Spano, C., Bernabei, D., Veronesi, E., Bertoni, F., Paolucci, P., Conte, P., and Horwitz, E.M. Restoration and reversible expansion of the osteoblastic hematopoietic stem cell niche after marrow radioablation. Blood 114, 2333, 2009.

32. Rasini, V., Dominici, M., Kluba, T., Siegel, G., Lusenti, G., Northoff, H., Horwitz, E.M., and Schafer, R. Mesenchymal stromal/stem cells markers in the human bone marrow. Cytotherapy 15, 292, 2013.

33. Dennis, J.E., Konstantakos, E.K., Arm, D., and Caplan, A.I. In vivo osteogenesis assay: a rapid method for quantitative analysis. Biomaterials 19, 1323, 1998.

34. Kuznetsov, S.A., Mankani, M.H., and Robey, P.G. In vivo formation of bone and haematopoietic territories by transplanted human bone marrow stromal cells generated in 
medium with and without osteogenic supplements. J Tissue Eng Regen Med 7, 226, 2013.

35. Cuomo, A.V., Virk, M., Petrigliano, F., Morgan, E.F., and Lieberman, J.R. Mesenchymal stem cell concentration and bone repair: potential pitfalls from bench to bedside. J Bone Joint Surg Am 91, 1073, 2009.

36. Caldwell, J., Palsson, B.O., Locey, B., and Emerson, S.G. Culture perfusion schedules influence the metabolic activity and granulocyte-macrophage colony-stimulating factor production rates of human bone marrow stromal cells. J Cell Physiol 147, 344, 1991.

37. Miao, D., Murant, S., Scutt, N., Genever, P., and Scutt, A. Megakaryocyte-bone marrow stromal cell aggregates demonstrate increased colony formation and alkaline phosphatase expression in vitro. Tissue Eng 10, 807, 2004.

38. Ahmadbeigi, N., Soleimani, M., Babaeijandaghi, F., Mortazavi, Y., Gheisari, Y., Vasei, M., Azadmanesh, K., Rostami, S., Shafiee, A., and Nardi, N.B. The aggregate nature of human mesenchymal stromal cells in native bone marrow. Cytotherapy 14, 917, 2012.

39. Weber, C., Pohl, S., Portner, R., Wallrapp, C., Kassem, M., Geigle, P., and Czermak, P. Cultivation and differentiation of encapsulated hMSC-TERT in a disposable small-scale syringe-like fixed bed reactor. Open Biomed Eng J 1, 64, 2007.

40. Rosova, I., Dao, M., Capoccia, B., Link, D., and Nolta, J.A. Hypoxic preconditioning results in increased motility and improved therapeutic potential of human mesenchymal stem cells. Stem Cells 26, 2173, 2008.

41. Jansen, J., Nolan, P.L., Reeves, M.I., Akard, L.P., Thompson, J.M., Dugan, M.J., and Hanks, S.G. Transportation of peripheral blood progenitor cell products: effects of time, temperature and cell concentration. Cytotherapy 11, 79, 2009.

42. Quan, R.F., Tang, Y.H., Huang, Z.M., Yang, D.S., Li, W., Xu, J.W., and $\mathrm{Wu}, \mathrm{X} . \mathrm{C}$. Difference of adherence, proliferation and osteogenesis of mesenchymal stem cells cultured on different HA/ZrO2 composites. Chin J Traumatol 15, 131, 2012.

43. Bernhardt, A., Lode, A., Peters, F., and Gelinsky, M. Comparative evaluation of different calcium phosphate-based bone graft granules-an in vitro study with osteoblast-like cells. Clin Oral Implants Res 24, 441, 2013.

44. Scaglione, S., Giannoni, P., Bianchini, P., Sandri, M., Marotta, R., Firpo, G., Valbusa, U., Tampieri, A., Diaspro, A., Bianco, P., and Quarto, R. Order versus disorder: in vivo bone formation within osteoconductive scaffolds. Sci Rep 2, 274, 2012.

45. Mankani, M.H., Kuznetsov, S.A., Marshall, G.W., and Robey, P.G. Creation of new bone by the percutaneous injection of human bone marrow stromal cell and HA/TCP suspensions. Tissue Eng Part A 14, 1949, 2008.

46. Ng, A.M., Tan, K.K., Phang, M.Y., Aziyati, O., Tan, G.H., Isa, M.R., Aminuddin, B.S., Naseem, M., Fauziah, O., and Ruszymah, B.H. Differential osteogenic activity of osteoprogenitor cells on $\mathrm{HA}$ and TCP/HA scaffold of tissue engineered bone. J Biomed Mater Res A 85, 301, 2008.

47. Burns, J.S., Rasmussen, P.L., Larsen, K.H., Schroder, H.D., and Kassem, M. Parameters in three-dimensional osteospheroids of telomerized human mesenchymal (stromal) stem cells grown on osteoconductive scaffolds that predict in vivo bone-forming potential. Tissue Eng Part A 16, 2331, 2010.

48. Griffon, D.J., Abulencia, J.P., Ragetly, G.R., Fredericks, L.P., and Chaieb, S. A comparative study of seeding techniques and three-dimensional matrices for mesenchymal cell attachment. J Tissue Eng Regen Med 5, 169, 2011.

49. Geesink, R.G. Osteoconductive coatings for total joint arthroplasty. Clin Orthop Relat Res 53, 2002.

50. Impens, S., Chen, Y., Mullens, S., Luyten, F., and Schrooten, J. Controlled cell-seeding methodologies: a first step toward clinically relevant bone tissue engineering strategies. Tissue Eng Part C Methods 16, 1575, 2010.

51. Zoellner, H., Hofler, M., Beckmann, R., Hufnagl, P., Vanyek, E., Bielek, E., Wojta, J., Fabry, A., Lockie, S., and Binder, B.R. Serum albumin is a specific inhibitor of apoptosis in human endothelial cells. J Cell Sci 109, 2571, 1996.

52. Garcovich, M., Zocco, M.A., and Gasbarrini, A. Clinical use of albumin in hepatology. Blood Transfus 7, 268, 2009.

53. Baltanas, F.C., Weruaga, E., Valero, J., Recio, J.S., and Alonso, J.R. Albumin attenuates DNA damage in primarycultured neurons. Neurosci Lett 450, 23, 2009.

54. Garcia-Gonzalo, F.R., and Izpisua Belmonte, J.C. Albuminassociated lipids regulate human embryonic stem cell selfrenewal. PLoS One 3, e1384, 2008.

55. Xu, C., He, D., Zeng, L., and Luo, S. A study of adsorption behavior of human serum albumin and ovalbumin on hydroxyapatite/chitosan composite. Colloids Surf B Biointerfaces 73, 360, 2009.

56. Benoit, D.S., Tripodi, M.C., Blanchette, J.O., Langer, S.J., Leinwand, L.A., and Anseth, K.S. Integrin-linked kinase production prevents anoikis in human mesenchymal stem cells. J Biomed Mater Res A 81, 259, 2007.

57. Marastoni, S., Ligresti, G., Lorenzon, E., Colombatti, A., and Mongiat, M. Extracellular matrix: a matter of life and death. Connect Tissue Res 49, 203, 2008.

58. Weszl, M., Skaliczki, G., Cselenyak, A., Kiss, L., Major, T., Schandl, K., Bognar, E., Stadler, G., Peterbauer, A., Csonge, L., and Lacza, Z. Freeze-dried human serum albumin improves the adherence and proliferation of mesenchymal stem cells on mineralized human bone allografts. J Orthop Res 30, 489, 2012.

59. Bonewald, L.F., Harris, S.E., Rosser, J., Dallas, M.R., Dallas, S.L., Camacho, N.P., Boyan, B., and Boskey, A. von Kossa staining alone is not sufficient to confirm that mineralization in vitro represents bone formation. Calcif Tissue Int 72, 537, 2003.

60. Di, G., Wang, J., Liu, M., Wu, C.T., Han, Y., and Duan, H. Development and evaluation of a trehalose-contained solution formula to preserve hUC-MSCs at 4 degrees C. J Cell Physiol 227, 879, 2012.

Address correspondence to: Massimo Dominici, MD

Laboratory of Cell Biology and Advanced Cancer Therapies Department of Medical and Surgical Sciences for Children $\mathcal{E}$ Adults University Hospital of Modena and Reggio Emilia Via Del Pozzo 71 41124 Modena Italy

E-mail: massimo.dominici@unimore.it

Received: April 22, 2013

Accepted: June 19, 2013

Online Publication Date: August 20, 2013 